\title{
A FICÇÃO DO CIENTISTA A RESPEITO DA "MODESTA PROPOSTA” DE SWIFT
}

\author{
Fernando Morato
}

Qual o sentido de trazer um panfleto político da Inglaterra do século XVIII para uma discussão a respeito de Ficção Científica? O que ele pode acrescentar a um campo de estudos que já está bastante bem delineado como pertencente prioritariamente aos séculos XIX e XX? (MENDLESOHN, 2003 p. 1-12).

$\mathrm{Na}$ verdade, acredito que o "modesto" texto de Jonathan Swift consegue atingir, já na primeira metade do século XVIII, de forma aguda, o cerne das questões fundamentais que a Ficção Científica se propõe a discutir, e o faz exatamente no momento em que essas questões estão começando a se apresentar historicamente mas ainda não tiveram força suficiente para configurar um gênero discursivo adequado para serem expressas, já que este só vai tomar forma plena no século seguinte. $\mathrm{O}$ costume de reconhecer como pertinentes ao gênero da Ficção Científica apenas aquilo que se identifica com os caminhos que foram trilhados a posteriori acaba ajudando a desfocar o nosso olhar para como Swift e outros escritores contemporâneos sugerem elementos sutis que poderiam muito bem ter sido fecundos para os autores seguintes, caso tivessem sido reconhecidos como tal e aproveitados literariamente.

Para tentar justificar a minha hipótese é preciso, como sempre é preferível em se tratando de literatura, primeiro, voltar nossa atenção 
para o próprio texto. Com título pomposo, a "Modesta proposta para evitar que as crianças da Irlanda sejam um fardo para os seus pais ou para o seu país" (SWIFT, 1993) foi editada anonimamente como panfleto em 1729, num momento da vida de Swift de prolífica atividade literária. Nos cinco anos entre 1727 e 1732, além da "Modest proposal", ele publicou ainda alguns volumes de Miscellanies, "Answer to a Craftsman", "Considerations upon Two Bills..." escreveu a maior parte de sua poesia, e preparou os quatro volumes de seus Collected Works, que começaram a ser publicados a partir de 1734 (DE GATEGNO, 2006, p. 437). Não demorou muito, entretanto, para a "Modesta proposta", já devidamente atribuída a Swift, se tornar um texto de referência no uso da ironia.

Vale lembrar que o recurso sistemático à ironia não surgiu espontaneamente em Swift. Ele havia sido aperfeiçoado por seus companheiros do Scriblerus Club, Alexander Pope, John Gay, William Congreve e John Arbuthnot, ao longo dos encontros desse clube político e intelectual, que se deram entre 1713 e 1714 e da convivência epistolar dos amigos após o fim dessas reuniões. Das discussões e trocas promovidas pelos confrades do Scriblerus saíram não só vários dos artigos do The Examiner (ainda que ele seja expressão de um convívio intelectual anterior ao clube propriamente dito) como as Gulliver Travels de Swift, a Beggars Opera de John Gay, o Dunciad de Pope e The History of John Bull de John Arbuthnot. Somada à tradição satírica que vinha desde a Antiguidade e ao discurso inflamado típico dos panfletos políticos, a ironia adquire com os membros do Scriblerus novas alturas e refinos (CARPEAUX, 1985, Vol. IV, p. 872-88o).

Voltando ao texto da "Modesta Proposta" de Swift. A partir da constatação do quadro lamentável que é a existência de um exército de mulheres pobres com várias crianças atrás de si nas ruas e estradas da Irlanda, crianças que, devido à falta de trabalho, estão destinadas a serem bandidos ou perecerem em batalhas e empresas comerciais, o narrador do texto (se assim podemos chamá-lo, já que não se apresenta como tal) começa a discutir algumas das propostas de que tomou conhecimento para diminuir o sofrimento dessas crianças, e descarta-as uma a uma por serem "grosseiramente equivocados em seus cálculos". Avança, então, mencionando que calculou que o gasto que as mães têm com seus filhos até um ano de vida é mínimo, já que as crianças podem ser alimentadas com leite materno, e, levando em consideração os 200.000 "casais reprodutores" do reino, vai sucessivamente fazendo descontos de famílias que têm condições de manter seus filhos, números de mortalidade infantil, diferenças entre número de homens e mulheres e termina por 
chegar a um total de 100.000 crianças sobreviventes que não poderão ser sustentadas por suas mães nem têm ainda condições de se dedicarem ao roubo (pelo menos até os seis anos de idade). Então, apelando para o testemunho de um amigo americano que afirma ser a carne de bebê um prato realmente saboroso, o narrador humildemente propõe que as 100.000 crianças que calculou anteriormente sejam vendidas como carne para as mesas de "pessoas de bem."

Os lucros que a venda de crianças podem gerar são calculados escrupulosamente: uma criança dá 2 shillings de gasto a seus pais em um ano ("andrajos incluídos") e, se vendida por 10 shillings, gerará um rendimento de 8 shillings! Sua pele pode, inclusive, ser usada como material para confecção de luvas e outros artigos finos de couro.

O narrador ainda abre espaço para rebater a sugestão de um amigo que propõe substituirem-se os cervos, que estão praticamente extintos nas terras dos senhores ingleses, por crianças pobres de 12 anos que poderiam muito bem ser caçadas, mas pondera que apesar de isto "quase beirar a crueldade", o fato é que a carne de um jovem de 12 anos, segundo o informante americano, é muito insípida e dura.

Retomando, então, seu raciocínio, narrador elenca as diversas vantagens de sua proposta: 1) seria reduzido o número de papistas (que são, em sua maioria, desprivilegiados); 2) os pobres poderiam ter, finalmente, algo de valor em sua propriedade; 3) seria diminuído em grande proporção o gasto do governo com o sustento de 100.000 crianças pobres; 4) a circulação de riquezas pelo país teria um verdadeiro incremento; 5) seria criada uma fonte de renda adicional para as reprodutoras regulares; 6) as tavernas teriam seu movimento reavivado; 7) receberiam grande incentivo tanto o casamento quanto o cuidado dos filhos além da consequente diminuição de abortos devidos a os maridos surrarem suas esposas; 8) aumentariam as exportações de carne de porco (já que esta seria substituída nas mesas inglesas pela de crianças); 8) diminuiria a carga de impostos sobre a Irlanda etc.

$\mathrm{O}$ "narrador" acrescenta ainda que

tendo [se] desgastado durante muitos anos propondo Pensamentos vãos, ociosos, visionários, e afinal desacreditado totalmente de seu Sucesso, felizmente descobri[u] esta Proposta que, sendo absolutamente nova, ainda possui algo de Sólido e Real (Id, ibid pp. 29-31).

já que é prática, simples, barata e eficiente. Desafia até os políticos a consultarem as famílias pobres para confirmarem se elas preferem receber algum dinheiro ou cuidar do sustento de suas crianças. 
O texto, ainda que publicado anonimamente, é sabidamente de Jonathan Swift e chegou até a fazer alguns levantarem suspeitas de que ele estivesse com algum comprometimento das faculdades (ou foi lido, a posteriori, como indício precoce da crise mental de que sofreu no final da vida), mas acho que é possível arriscar uma leitura em outra direção e enriquecê-la justamente com certas questões que são suscitadas pelo gênero da Fiç̧ão Científica.

É interessante começar pelo fato de que, apesar de ser escrito em primeira pessoa, o texto não ter nenhuma marca clara de autoria, nem de Swift nem de nenhum outro possível escritor inglês do momento, evitando até marcas mais genéricas de subjetividade. A única menção que poderia ser considerada como indício de exposição biográfica é a afirmação que encerra a proposta (confirmando o quanto ela é desinteressada): "Não tenho filhos através dos quais eu pudesse esperar conseguir um simples tostão, o mais novo tendo nove anos e minha esposa tendo ultrapassado a idade de procriar." (Id, ibid, p. 33) À parte esta declaração de "desinteresse", todo o texto é marcadamente impessoal, o que me levou a chamar o enunciante de "narrador." Sei bem que a questão da identidade entre autor e enunciante de um texto, no século XVIII, é bem mais complexa, mas por ora nos baste reconhecer a neutralidade e distanciamento com que ele faz questão de apresentar os raciocínios mais bárbaros.

Ao longo do meu resumo da "Proposta," citei apenas um único trecho mais longo do qual acho que algumas palavras são bem ilustrativas: as propostas contrárias às do narrador são descritas como "Pensamentos vãos, ociosos, visionários." São algumas das imagens e adjetivos típicos que mais tarde, no momento da configuração de um cânone propriamente dito da Ficção Científica, serão a ela associadas. São também imagens que se dizem respeito a outros textos que estão sendo escritos pela mesma época e que serão futuramente considerados cofundadores desse "cânone", como por exemplo A Utopia, de Thomas Morus, a New Atlantis, de Francis Bacon, o Somnium, de Johannes Kepler e o L'autre monde, de Cyrano de Bergerac (STABLEFORT, 2003). Estas obras, mais claramente políticas que os textos de Ficção Científica, são todas livros que, em algum aspecto, apontam tanto para esse caráter visionário como para uma situação de ocioso desprendimento para viajar e conhecer o mundo, disposição que é várias vezes identificada como a base de certa linhagem da Ficção Científica ${ }^{\text {. }}$

1 É interessante registrar que a afirmação inicial de que criancinhas sejam servidas como iguarias vem de "um Americano muito entendido, conhecido meu que mora em Londres” (SWIFT, 1993, p. 9-11) 
Além disso, é justamente o "senso de maravilha" (conforme a observação que Farah Mendelsohn [2003] faz sobre a essência dos textos de Ficção Científica) que vai marcar essas primeiras obras, aproximando-as, igualmente, da literatura de viagens, já relativamente bem configurada e, em alguns casos, como acontece na Utopia, explicitamente mencionadas nesse universo intertextual que se cria (HEXTER, 1952).

Swift aponta, então, ao longo de um texto que perturba e desconcerta, para todo um universo de referências que se está configurando à época: há uma menção explícita a um "americano" (representante desse mundo ainda meio incógnito, bárbaro e fascinante), há menções a certos sonhos visionários, a propostas de construir um mundo melhor (ou ao menos de melhorar a realidade imediata, propostas por "Planejadores"). Não é possível falar em Fiç̧ão Científica, mesmo porque ainda não se trata de um gênero com claras convenções textuais e retóricas, como eram os diversos outros (a epopéia, a tragédia, a égloga), mas há razoáveis referências a uma série de práticas textuais que estão esboçando certa rota de cruzamentos extremamente complexa, que inclui também o panfleto, a sátira política e o ensaio.

Ao se situar nesse universo em formação das "propostas visionárias" (muitas veiculadas em panfletos anônimos como o dele), o narrador introduz também um outro referencial discursivo importante que é o da praticidade e do cálculo. A vantagem da sua proposta é, em oposição às dos visionários, ser "sólida e real," que é exatamente o tipo de qualidade que vem sendo reivindicada por um dos campos de reflexão que se montam ao longo do século XVII: a ciência. Não fazia mais de cem anos que Galileu Galilei havia escrito "O ensaiador" para rebater as críticas de Lotário Sarsi Sigensando ao seu Nuncio Sidereo, afirmando princípios como:

\begin{abstract}
A filosofia encontra-se escrita neste grande livro que continuamente se abre perante nossos olhos (isto é, o universo), que não se pode compreender antes de entender a língua e conhecer os caracteres com os quais está escrito. Ele está escrito em língua matemática, os caracteres são triângulos, circunferências e outras figuras geométricas, sem cujos meios é impossível entender humanamente as palavras; sem eles nós vagamos perdidos dentro de um obscuro labirinto (GALILEI, 1978, p. 119).
\end{abstract}

É a "língua matemática," sem exatamente "triângulos e circunferências", mas com cálculos e proporções que o narrador da "Modesta Proposta" utiliza o tempo todo. Os ganhos da coroa, dos cavalheiros, dos taverneiros, dos açougueiros e dos próprios pobres são escrupulosamente medidos, somados, divididos e demonstrados. Ele se 
apropria de um universo textual e retórico que se vem configurando ao longo do século anterior e utiliza-o para expor algumas contradições que esse mesmo universo textual não consegue resolver. ${ }^{2}$

É importante notar que a liberdade no tratamento de materiais textuais diversos que se apresentavam ao público leitor nascente na Inglaterra do início do século XVIII não foi um traço exclusivo de Swift, mas uma das características que distinguiram a atuação dos membros do Scriblerus Club que mencionamos atrás. Boa parte da eficiência retórica conseguida pelos Tories (os "conservadores") que faziam parte do clube se deve à manipulação de expectativas e fórmulas que, como já foi dito, trabalhavam de forma inteligente a ironia. Swift, como seus colegas, se apropria sistematicamente dos discursos, tanto os consagrados quanto os em formação e joga abertamente com os seus sinais. ${ }^{3}$

O procedimento empregado na "Modesta proposta", a racionalização do mundo, é muito semelhante ao que se configura no discurso científico em formação (ao lado de Galileu, Kepler, Christiaan Huygens, Isac Newton são cientistas que, como escritores, se responsabilizarão pelo estabelecimento das estratégias retóricas do texto técnico) mas também é semelhante ao que alguns dos principais autores de ficção científica dos séculos XIX e XX adotaram, com a diferença fundamental de que estes o fizeram no campo do conteúdo textual mais do que no próprio discurso. A ciência, para eles, é um acervo de assuntos mais do que de práticas discursivas: Mary Shelley descreve as angústias vividas pela criatura de Victor Frankenstein e os conflitos que a consciência de seus feitos causam no doutor; H. G. Welles faz o narrador de A guerra dos mundos refletir de forma desencantada sobre as limitações da humanidade frente à superioridade tecnológica e bélica dos marcianos; Aldous Huxley descreve suas personagens às voltas com os conflitos gerados pela sociedade planificada em que vivem e os impulsos humanos que ultrapassam esses limites estreitos; entretanto, os relatórios de experiências, as notas de trabalho, os artigos de divulgação estão todos ausentes. Temos as cartas de Victor Frankenstein, mas não seu diário de trabalho. Em nenhum momento as barbáries e desumanidades da ciência são narradas “de dentro.” Descrições externas ou conflitos entre

2 "Science fiction is part of a polysemic discourse" (MENDLESOHN, 2003, p. 10).

3 É este mesmo movimento que está na base do renascimento no século XVIII de um tipo de texto que desafia a compreensão moderna: o poema herói-cômico, que não pode ser compreendido fora do universo de práticas textuais extremamente regradas no qual foi escrito. Autor de alguns dos importantes poemas herói-cômicos (mock-heroic), Alexander Pope foi um dos membros ativos do Scriblerus club. 
personagens que se descobrem deslocados no "admirável mundo novo" são de certo modo o desenvolvimento que foi mais comum da literatura que mais propriamente foi chamada de "Ficção Científica", e em certa medida esse desenvolvimento era anunciado pela outra literatura de "proto-ficção-científica" do século XVIII, em que a o maravilhoso (o "visionário") era também o objeto fundamental, mas sempre narrado de fora.

É por isso que o texto de Swift se mostra tão fecundamente interessante. Se é possível, hoje, considerar que um dos traços mais importantes da literatura de Ficção Científica é justamente a exposição das fissuras geradas pelo mundo em que a consciência técnica de certa forma anula a consciência humana (MENDLESOHN, 2003), como a constatação da contradição entre o mundo vislumbrado da utopia e a realidade que se impôs acima (e apesar) da "visão", é também possível ler a "Modesta proposta" como um diagnóstico precoce dessas mesmas fissuras, mas que tem a sensibilidade de reconhecer um aspecto diferente (e fundamental).

Swift, que também se dedicou à fantasia crítica de caráter visionário nas Viagens de Gulliver, já consegue perceber que um dos problemas que se encontram na base da nova sociedade que começa a tomar forma durante a Revolução Industrial é justamente a cisão entre a consciência humanista e a retórica científica (mais tarde, encenado nas discussões entre Victor Frankenstein e sua monstruosa criatura). Por isso insisti desde o início em chamar o enunciante da "Modesta Proposta" de narrador: é bem possível identificá-lo como uma representação literária da persona que assume o discurso científico nascente, ou mais precisamente do discurso da Economia (que está começando também a se configurar enquanto campo independente de saber - Adam Smith nasce em 1723). Tudo está presente: números, contingentes, fluxos, despesas, lucros etc:

A proposta que, portanto, humildemente ofereço à apreciação do público, é que das cento e vinte mil crianças já calculadas, vinte mil sejam reservadas para a reprodução, das quais uma quarta parte apenas fosse de machos; o que é mais do que admitimos para ovelhas, bovinos ou suínos, e meu argumento é que estas crianças raramente são fruto do matrimônio, circunstância não muito levadas em conta por nossos selvagens, um macho sendo portanto suficiente para servir a quatro fêmeas (SWIFT, 1993 p. 11).

São "machos", "fêmeas", "reprodutores", mas não pessoas. Este é o único "erro" da proposta apresentada por Swift. Não estamos longe da descrição da fábrica eugênica do início de Admirável mundo novo: 
Porque, é bem de ver - disse o Sr. Foster - na imensa maioria dos casos a fecundidade é simplesmente um incômodo. Um ovário fértil em mil e duzentos, eis o que seria plenamente suficiente para nossas necessidades. Mas nós queremos ter boa possibilidade de escolha. E, naturalmente, é preciso conservar sempre uma margem de segurança enorme. Por isso deixamos que se desenvolvam normalmente até trinta por cento de embriões femininos. Os outros recebem uma dose de hormônio sexual masculino a cada vinte e quatro metros, durante o resto do percurso. Resultado: são decantados como neutros - absolutamente normais sob o ponto de vista da estrutura (salvo, viuse obrigado a reconhecer, o fato de terem, na verdade, uma ligeira tendência para o aparecimento de barba), mas estéreis. Garantidamente estéreis. O que nos leva por fim - continuou o Sr. Foster - a deixar o domínio da simples imitação servil da natureza para entrar no mundo muito mais interessante da invenção humana (HUXLEY, 1979, p. 14).

Mas ao mesmo tempo não estamos longe dos primeiros economistas mercantilistas que já estão escrevendo alguns tratados na França (Jean-Baptiste Colbert, o nome mais importante entre os Fisiocratas, desenvolveu sua ação na segunda metade do século XVII) e, na Inglaterra, estão se manifestando justamente através de panfletos, o gênero textual escolhido por Swift.

Este é um fato que reforça a minha ideia de uma leitura da "Modesta Proposta" na chave do simulacro ou sátira ao discurso científico nascente: além dos elementos discursivos dos quais o narrador se apropria, o próprio veículo do texto é o preferido pelos polemistas políticos e econômicos. Não esqueçamos que há ainda nessa época uma mistura muito grande entre os terrenos filosófico, político, científico, como exemplifica a ação de Isaac Newton como guardião da Casa da Moeda (entre 1696 e 1703) alguns anos antes de se tornar presidente da Royal Society. (WHITE, 2000)

Vale a pena, nesta altura, fazer uma digressão para trazer para o lado da "Modesta proposta" um outro texto do círculo de autores do Scriblerus $c l u b$ que pode formar com ela um díptico iluminador. Trata-se de "A arte da mentira política”, escrito e publicado por John Arbuthnot (1667-1737) em 1712, mas atribuído a Swift não só nas Miscellanies que ele publicou em conjunto com Alexander Pope em 1727, mas também numa tradução francesa impressa na Holanda em 1733. John Arbuthnot, médico da rainha e escritor discreto, não se preocupava com essas questões de atribuição e muitas vezes se contentava em figurar como inspirador de certas ideias depois desenvolvidas pelos membros do Scriblerus. Sem grandes ciúmes, cedeu a paternidade da personagem arquetípica John Bull a seus colegas.

O texto trata de um assunto (a mentira política) que já fora objeto de apreciação do jornal satírico The Examiner em 1710, e se apresenta de 
maneira curiosa, como a proposta de subscrição de uma obra que está no prelo. O possível assinante é informado do conteúdo dos onze capítulos em que se divide o primeiro volume dessa arte da Pseudologia (o autor fez dois volumes, mas do segundo, nada é dito). No prefácio, explica o candidato a editor, o autor

afirma que as artes consistem primeiramente em teoremas e em práticas, dispersas de um lado e de outro, transmitidas de mão em mão entre os professores, reveladas somente às crianças da Arte, até que apareça um grande gênio que recolha as propostas separadas e desunidas e as reduzam em um sistema regular. É o caso em que se encontra hoje a Arte da mentira política, esta obra tão útil e nobre; no último século tem sido enriquecida de várias novas descobertas, (...) pode-se a justo título, pretender ter um lugar na Enciclopédia (SWIFT, 2006, p. 34).

"Arte" desenvolvida em paralelo ao discurso científico, a mentira política, que teve seu reconhecimento formal feito por Maquiavel em $O$ príncipe (cujo manuscrito final data de 1513). Lembremos de passagem o famoso trecho em que ela adquire cidadania:

Se os homens fossem todos bons, esse preceito [faltar com a palavra empenhada quando houver motivos para isto] não seria bom, mas como são pérfidos e não mantêm a sua palavra em relação a ti, da mesma maneira não tens de mantê-la em relação a eles. Nunca faltaram a um príncipe razões legítimas com que mascarar as inobservâncias. Disso poder-se-iam oferecer numerosos exemplos modernos e mostrar quantas convenções de paz, quantas promessas se fizeram írritas e vãs em razão da infidelidade dos príncipes; e que aquele que melhor soube usar a natureza da raposa teve mais êxito. Mas é necessário saber bem disfarçar essa natureza e ser grande simulador e dissimulador. E são tão simples os homens e tanto obedecem às necessidades presentes, que aquele que engana encontrará sempre quem se deixe enganar (MAQUIAVEL, 1987, p. 112).

Maquiavel é desiludidamente objetivo a respeito da natureza dos homens ("são pérfidos e não mantêm a sua palavra em relação a ti") e isto lhes abre o flanco ao príncipe igualmente inescrupuloso. Não é o mesmo que reconhece o autor da "Arte da mentira política": no livro atribuído a Swift ela é tratada como uma atividade exclusiva de certas pessoas, restringindo-se às classes privilegiadas:

É necessário perceber que o povo tem direito de esperar que seus vizinhos lhe digam a verdade nos assuntos particulares; que cada um tem direito à verdade econômica, ou seja, que cada um tem direito de exigir que os membros de sua família lhe digam a verdade, a fim de não serem enganados por sua mulher, pelos seus filhos, nem pelos seus empregados domésticos; mas que não há 
nenhuma espécie de direito sobre a verdade política e que o povo possui menos o direito de querer ser instruído sobre a verdade em matéria de governo do que o de possuir bens, terras, casas senhoriais (SWIFT, 2006, p. 37-38).

Sinceridade priva da que é respondida com mentira política. Depois, o autor se alonga na taxionomia dos tipos de mentiras e no modo mais eficiente de divulgá-las, o que consiste o corpo propriamente dito da obra. Seria divertido avançar por esses irônicos meandros da Pseudologia, mas baste-nos uma última citação, da proposta do último capítulo, que versaria sobre a questão de qual seria mo meio mais eficiente de vencer a mentira: a verdade ou outra mentira. $\mathrm{O}$ candidato a editor do texto adianta ao possível leitor que o autor do tratado "está convencido de que o meio mais limpo e mais eficaz para destruir uma mentira é lhe opor uma outra mentira".

Da mesma forma que a "Modesta Proposta", certas ideias desconfortáveis são apresentadas na "Arte da mentira política" da maneira mais direta e seca possível. Mas um ponto diferencia os dois textos, que é a atitude de seus enunciantes frente aos leitores: na primeira, ele se mostra de forma neutra, fria, enquanto na segunda, procura aliciar e encantar seu futuro assinante.

O interessante é notar como essas estratégias textuais diferentes se associam a tipos diferentes de matérias. A "Proposta", direta, racional e objetiva trata da "realidade empírica" da pobreza, enquanto a "Arte", sedutora, argumentativa, quase emocional, é a reunião por um "grande gênio" das práticas dispersas da sociedade. As duas matérias, que são complementares (a realidade social e o discurso social), correspondem a estratégias textuais opostas mas que, ao mesmo tempo, se completam. O absurdo da antropofagia economicamente legitimada é objeto do discurso seco, realista, científico, enquanto a prática da política, que pressuporia certa transparência ligada à justiça, é objeto de ficção sobre ficção (como explicita o último capítulo).

O círculo do Scriblerus club mostra, como já dito, plena consciência da importância definidora das práticas textuais na constituição dos significados latentes. Quando John Arbuthnot, autor da "Arte da mentira política” escolhe apresentá-la como proposta de publicação para futuros assinantes, faz uma insinuação interessante de que a mentira está na dependência direta do interesse do mercado. $\mathrm{O}$ "candidato a editor" que a apresenta não se esquiva de fazer elogios abertos ao texto que tem a publicar, procurando claramente conseguir o favor de seus assinantes. O direito à mentira, como já citado, não é privilégio de todos, mas seu consumo está garantido. 
É opostamente complementar o tom reservado e calculado do narrador da "Modesta Proposta", que procura deixar as emoções do leitor afastadas em todos os momentos (tanto que faz apenas um discreto comentário de que a caça de meninos de 12 anos "beira um pouco a Crueldade"). Discurso racionalmente concebido, ele se sustenta apenas na utilidade, praticidade e objetividade:

\begin{abstract}
Algumas Pessoas desanimadas de Espírito estão bastante preocupadas com este imenso número de Pobres Idosos, Doentes e Mutilados e tenho sido solicitado a empregar meu Pensamento para encontrar alguma possível solução que alivie a Nação de tão penoso Fardo. Mas esta questão não me preocupa nem um pouco, pois é bem sabido que eles estão a cada dia morrendo e apodrecendo, de frio e de fome, e de sujeira, e de vermes, tão rapidamente como se possa razoavelmente esperar (SWIFT,1993, p. 19).
\end{abstract}

O que presenciamos é, como disse acima, uma possibilidade de díptico textual em que cada um deles ilumina a parte deixada na sombra pelo outro. Curiosas complementaridades desses panfletos: o que descreve uma situação absurda é o mais "objetivo", enquanto o que trata da situação mais prática se sustenta numa instável e futura assinatura fictícia; um dá forma ao discurso bárbaro enquanto o que trata do discurso já reconhecido por Maquiavel há duzentos anos nem sequer existe; o anônimo pertence a Swift, enquanto o que lhe é atribuído não saiu diretamente de sua pena.

São dois campos discursivos (o da ciência e da política moderna) que se configuram em paralelo e que vão, no futuro, se valer da mesma autoridade para imporem suas legitimidades:

Il nous appartient de soumettre au joug bienfaisant de la raison tous les êtres inconnus, habitants d'autres planètes, qui se trouvent peut-être encore à l'état sauvage de la liberté. S'ils ne comprennent pas que nous leur apportons le bonheur mathématique et exact, notre devoir est de les forcer à être heureux. Mais avant toutes autres armes, nous emploie-rons celle du Verbe.

É a citação que Eugène Zamiatine diz ter lido publicada no Journal Nacional (ZAMIATINE, 1920, p. 6). É a mesma bonheur mathématique et exact que Swift descreveu através de seu narrador ("Sólida e Real" é sua Proposta), completada pelo mesmo direito exclusivo de uma minoria de contar suas próprias mentiras, explicitada na "Arte da mentira pol'litica". Estes textos visionários de entre 1710 e 1730 estão, na verdade, dando forma verbal para realidades prementes que se mostram aos olhos de quem quiser enxergar. 
A ficção científica ainda não se definiu enquanto gênero autônomo, mas todos os elementos que são considerados necessários para sua configuração já estão presentes na Inglaterra do início do século XVIII. O que acredito que Swift (e seus companheiros do Scriblerus club) faz é reconhecer as potenciais contradições que se estão formando e o quanto alguns tipos particulares de discurso que também se configuram não estão de modo algum isolados dessas contradições a que a sociedade está cada vez mais se submetendo. A neutralidade e distanciamento a que o narrador da "Modesta Proposta" submete seus "objetos" servem justamente para anulá-los enquanto seres humanos e evidencia papel que eles efetivamente estão assumindo na sociedade capitalista que se forma: não mais "membros da Igreja”, "exército de Cristo" ou "rebanho de deus", mas simplesmente mercadorias e propriedade:

Aumentaria o Cuidado e a Ternura das Mães para com seus filhos, estivessem elas seguras de estarem seus pobres Bebês com a Vida encaminhada, de certa forma graças ao Público, para seu Lucro anual ao invés de despesa. Deveríamos rapidamente notar uma saudável Competição entre as Mulheres Casadas, para ver qual delas levaria ao Mercado a Criança mais gorda. Os Homens passariam a gostar de suas Mulheres durante o Período da Gravidez, tanto quanto gostam atualmente de suas Éguas ou Vacas prenhes, ou de suas Porcas a ponto de parir, e não se disporiam a batê-las ou chutá-las (como é prática tão frequente) por medo de um Aborto (SWIFT, 1993, p. 25).

Num mundo em que tudo é tecnicamente tratado em termos de praticidade, lucro e eficiência, o pastor Jonathan Swift reconhece que o único vínculo "afetivo" duradouro e real é justamente o interesse, enquanto o médico John Arbuthnot reconhece que a melhor maneira de vencer uma mentira é lhe opor outra mentira mais verossímil - à barbárie social se soma a barbárie intelectual. A mensuração e hierarquização sistemática da realidade, que é um benefício evidente da ciência, também pode gerar pesadelos de brutalidade a partir do momento em que absolutamente tudo pode ser quantificado e submetido à frieza calculista. E isto não se dá apenas na realidade exterior que se está descobrindo e alarga os horizontes para esse "admirável mundo novo" que se torna objeto tanto da literatura de viagens quanto da tateante literatura "visionária", faz parte de uma retórica da conversão do próprio discurso em uma prática de objetivação desse mundo. O discurso lúcido dos tecnocratas de campos de concentração ou das faxinas étnicas já está embrionariamente compreendido e exposto na sua metódica frieza. 
No extremo oposto, a "verdade" não faz nenhuma questão de ser apresentada, mesmo porque é ineficiente. A citação do Journal national feita por Eugène Zamiatine, continua com a seguinte afirmação:

Au nom du Bienfaiteur, ce qui suit est annoncé aux numéros de l'État Unique : Tous ceux qui s'en sentent capables sont tenus de composer des traités, des poèmes, des proclamations, des manifestes, des odes, etc., pour célébrer les beautés et la grandeur de l'État Unique (ZAMIATINE, 1920, p. 7).

Todos os "números" do Estado Único têm direito de dizer a mesma coisa: as belezas desse mesmo Estado Único, afinal só a alguns é reservado o direito da liberdade de mentira política. Discurso político que não diz a realidade e discurso científico que não tem capacidade de enxergar essa realidade.

Se cento e cinquenta anos mais tarde Machado de Assis, outro mestre da ironia, vai explicitar os becos sem saída da mente científica naquele Simão Bacamarte que não tem outra alternativa a não ser reconhecer que o seu discurso integralmente racional e frio é a verdadeira loucura, ao mesmo tempo em que os diversos discursos políticos se aproveitam da sua inocência para se digladiarem pelo poder em Itaguaí, Swift e os seus amigos do Scrilberus club lançam mão de outra estratégia, fazendo o leitor confrontar-se diretamente com a frieza e o racionalismo alienantes a que o discurso científico pode chegar dando voz à própria enunciação fria e racional desse discurso.

O "mundo científico" da "Modesta proposta" é menos uma realidade autônoma que vai ser observada e descrita com olhos fascinados ou horrorizados, mas antes criação dessa nova personagem (esse futuro Simão Bacamarte), uma máscara retórica atrás da qual o indivíduo se esconde das responsabilidades ética e política de suas ideias e práticas. Daí, creio, poder já inserir o panfleto de Swift num conjunto de referências literárias mais amplo que o da sua própria época. A construção desse narrador/cientista anônimo (em oposição ao vendedor/técnico da "Arte da mentira política") ajuda a mostrar, "em ação", aquilo que boa parte da posterior Ficção Científica vai "encenar à distância”, aquilo que perturba e desconcerta em toda leitura atenta da "Modesta Proposta" de Swift: que seu discurso deixa de lado um detalhe incômodo a todo o construto intelectual prometido por essa ficção que é mundo de maravilhas da modernidade: os próprios seres humanos. 


\section{4 - Remate de Males 32.2 \\ REFERÊNCIAS BIBLIOGRÁFICAS}

CARPEAUX, Otto Maria. Historia da Literatura Ocidental. Vol IV Rio de Janeiro, Alhambra, 1985 .

DE GATEGNO, Paul J. Critical companion to Jonathan Swift: a literary reference to his life and work New York, Facts on File, 2006.

GALILEI, Galileu "O ensaiador", tradução de Nestor Deola, in Bruno, Galilei, Campanella Coleção Os Pensadores. São Paulo: Abril Cultural, 1978.

HEXTER, J. H. More's Utopia, the biography of na idea. New York/London: Harper Torchbooks, 1952.

HUXLEY, Aldous, Admirável mundo novo. Tradução de Vidal de Oliveira e Lino Vallandro. $5^{\text {a }}$ edição. Porto Alegre: Globo, 1979.

MAQUIAVEL, Nicolau. O Príncipe. Tradução, introdução e notas de Antonio D’Elia. São Paulo Cultrix/Círculo do Livro, 1987.

MENDLESOHN, Farah, "Reading science fiction", in Cambridge companion to science fiction, Cambridge: Cambridge University Press, 2003.

STABLEFORT, Brian "Science fiction before the genre", in Cambridge companion to science fiction, Cambridge: Cambridge University Press, 2003.

SWIFT, Jonathan, A arte da mentira política - precedido pelo texto "O mentir verdadeiro" de Jean-Jacques Courtine. Tradução Mônica Zoppi-Fontana e Roberto Leiser Baronas. Campinas: Pontes, 2006.

. Modesta proposta para evitar que as crianças da Irlanda sejam um fardo para seus pais e seu país. Tradução de Dorothée de Bruchard (edição bilíngue a partir do texto da edição de 1729), Porto Alegre: Paraula,1993.

WHITE, Michael C. Isaac Newton, o último feiticeiro. Tradução Maria Beatriz Medina. Rio de Janeiro/São Paulo: Record, 2000.

ZAMIATINE, Eugène. Nous Autres, traduit du russe par B. Cauvet-Duhamel. Édition du groupe «Ebooks libres et gratuits». Disponível em: http://www.didactibook.com/ produit/4329/978600o005320/Nous\%20Autres 